\title{
Entrustment Decision-Making in Competency-Based Teaching and Assessment in Health Professions Education
}

\author{
Olle ten Cate ${ }^{1}$
}

Published online: 10 November 2016

(C) International Association of Medical Science Educators 2016

Workplaces are essential for the education of professionals. While there is an increasing call for valid assessment of trainees to meet predefined competence standards [1-3], workplaces have traditionally not been well structured for the evaluation of learner competencies [4, 5]. Dynamic, reallife workplaces in professional domains cannot be standardized, as the problems professionals face are to some extent always unique. Much of the assessment of learners in the workplace involves single trainees, single assessors, and unique contexts (e.g., dealing with a unique patient), leading to persistent psychometric problems, such as rater leniency bias or generosity error, halo effects, restriction of range, poor discrimination between trainees, lack of documentation of deficits, low intra-rater and inter-rater, and cross-occasion consistency [6-8]. In terms of the Standards for Educational and Psychological Testing sources of validity evidence, there is legitimate concern about response process (low accuracy and quality of the scoring) and internal structure (low reproducibility), relationship to other variables (poor generalizability) and consequences (hardly any trainee "fails" a workplace internship). Many authors have attempted to capture the requirements of workplace environments for effective learning [9-11] and realize that workplace-based assessment should not be treated the same way as assessment in classrooms and courses, but must incorporate critical workplace conditions, such as the expectation to provide safe, effective, and patient-centered care $[12,13]$.

Olle ten Cate

t.j.tencate@umcutrecht.nl

1 Center for Research and Development of Education, University Medical Center Utrecht, P.O. Box \# 85500, 3508

GA Utrecht, The Netherlands
Many clinicians, forced to evaluate trainees on general competencies, feel unsure what scores to give. In contrast, when asked: Can this trainee be trusted to carry out this activity without your direct supervision? a more reliable answer can be expected [14]. Clinical activities that have the property that you can entrust them to trainees, when they have demonstrated the required competencies to be ready to do this, have been called Entrustable Professional Activities (EPAs) [15-17]. EPAs are part of essential professional work in a given context, require adequate knowledge, skill, and attitude, generally acquired through training, lead to recognized output of professional labor, are usually confined to qualified personnel, are executable independently of other tasks, within a time frame, are observable and measurable in their process and their outcome, and reflect one or more of the competencies to be acquired.

If a clinical training program is well described in their clinical activities, EPAs can serve as the building blocks of a workplace curriculum, can be the primary focus of assessment of learners, and can provide clear objectives for learning and practice. Instead of attempting to evaluate separate competencies of trainees, such as knowledge, communication skill, collaboration skill, and professionalism, EPAs integrate these and focus on the task as a whole. Table 1, adapted from Ten Cate \& Scheele [18], shows how EPAs in obstetrics require multiple competencies in an integrated fashion.

It is hard to think of any EPA that would not integrate several competencies. The assessment of trainees should therefore primarily focus on EPAs (horizontal dimension), not on separate competencies (the vertical dimension). When evaluating learners, specifically those with marginal performance, a well-described EPA mapped to competencies will then enable a more valid judgment and tailored feedback to learners. So the first question is: can the trainee do this in all respects? and only secondly: if not, why not? 
Table 1 Mapping EPAs to the most important competency domains

\begin{tabular}{|c|c|c|c|c|c|c|c|}
\hline Competencies EPAs & Medical expert & Communicator & Collaborator & Leader & Scholar & Health advocate & Professional \\
\hline Uncomplicated pregnancy & $\bullet$ & & & & & $\bullet$ & $\bullet$ \\
\hline Normal delivery & $\bullet$ & $\bullet$ & $\bullet$ & & & $\bullet$ & $\bullet$ \\
\hline Uncomplicated puerperium and neonate & - & & & & & $\bullet$ & \\
\hline High-risk complicated delivery & $\bullet$ & $\bullet$ & $\bullet$ & $\bullet$ & & & \\
\hline Perioperative care & $\bullet$ & $\bullet$ & & & & $\bullet$ & $\bullet$ \\
\hline Low-risk surgery & $\bullet$ & & $\bullet$ & & & & \\
\hline Breaking bad news conversation & & $\bullet$ & & & & & $\bullet$ \\
\hline
\end{tabular}

When an EPA is fully mastered, the trainee may be granted permission to act unsupervised, while a different EPA may require more time a practice. Likewise, for a different trainee, the moments of summative entrustment decisions or certification for EPAs may differ. An EPA is like driving a car-as soon as the learner has demonstrated competence, he or she may be certified to practice without supervision.

EPAs have become popular and many undergraduate and postgraduate medical programs in the USA and other countries have now described their programs using EPAs [19-21].

Assessing learners based on EPAs differs from traditional assessment in the clinical workplace. EPAs are geared to entrustment decisions. An entrustment decision includes not only the evaluation or ability or competence, but it also grants the permission to act under a designated level of supervision (e.g., direct supervision, indirect supervision, distant supervision), and enables to schedule trainees for clinical service [22, 23]. It essentially changes the nature of assessment of learners in the workplace and enables to acknowledge trainees' readiness for unsupervised practice of specified units of professional work and, thus, gradually allows them to become a practitioner, complying with the principle of competency-based medical education: certification based on competence rather than on time in training.

Entrustment decisions as assessment include patients in the equation (is it safe to leave the student alone to act with this patient?) and also the liability of the supervisor. Trusting a trainee with your patient means making yourself vulnerable. It includes taking a calculated risk that adverse events are manageable. Entrustment decisions allow trainees to carry out activities that supervisors may not have been able to observe and learners may have never encountered before, as each patient is different and may pose new challenges. Entrustment decisions therefore require an estimation of adaptive competence of the learner.

It is likely that the leniency bias, so prevalent in workplacebased assessments, will to some extent be countered, if the assessment is an entrustment decision to work with patients without direct supervision. A "marginal pass" may harm the patient [24]. EPAs and the entrustment decisions that come with this concept may thus help to improve the current workplace-based assessment practices.

\section{References}

1. Frank JR, Snell LS, ten Cate O, Holmboe ES, Carraccio C, Swing SR, et al. Competency-based medical education: theory to practice. Med Teach. 2010;32(8):638-45.

2. Cooke M, Irby D, O'Brien BC. Educating physicians - a call for reform of medical school and residency. Jossey-Bass/Carnegie Foundation for the Advancement of Teaching: Hoboken; 2010.

3. Nasca T, Philbert I, Brigham T, Flynn TC. The next GME accreditation system - rationale and benefits. N Engl J Med. 2012;366(11):1051-6.

4. Lurie SJ, Mooney CJ, Lyness JM. Commentary: pitfalls in assessment of competency-based educational objectives. Acad Med. 2011;86(4):412-4.

5. Lurie SJ, Mooney CJ, Lyness JM. Measurement of the general competencies of the accreditation council for graduate medical education: a systematic review. Acad Med. 2009;84(3):301-9.

6. Govaerts MJB, van der Vleuten CPM, Schuwirth LWT, Muijtjens AMM. Broadening perspectives on clinical performance assessment: rethinking the nature of in-training assessment. Adv Health Sci Educ Theory Pract. 2007;12(2):239-60.

7. Albanese M. Challenges in using rater judgements in medical education. J Eval Clin Pract. 2000;6(3):305-19.

8. Massie J, Ali JM. Workplace-based assessment: a review of user perceptions and strategies to address the identified shortcomings. Adv Heal Sci Educ. 2015;EarlyOnline.

9. Billett S. Constituting the workplace curriculum. J Curric Stud. 2006;38(1):31-48.

10. Teunissen PW. Unravelling learning by doing. Doctoral Dissertation. Amsterdam: VU University; 2009

11. Eraut M. Learning from other people in the workplace. Oxf Rev Educ. 2007;33(4):403-22.

12. Kogan JR, Conforti LN, Iobst WF, Holmboe ES. Reconceptualizing variable rater assessments as both an educational and clinical care problem. Acad Med. 2014;89(5):1-7.

13. Crossley J, Jolly B. Making sense of work-based assessment: ask the right questions, in the right way, about the right things, of the right people. Med Educ. 2012;46(1):28-37.

14. Weller JM, Misur M, Nicolson S, Morris J, Ure S, Crossley J, et al. Can I leave the theatre? A key to more reliable workplace-based assessment. Br J Anaesth. 2014;112(March):1083-91.

15. ten Cate O. Entrustability of professional activities and competency-based training. Med Educ. 2005;39(12):1176-7. 
16. ten Cate $\mathrm{O}$. Nuts and bolts of entrustable professional activities. $\mathrm{J}$ Grad Med Educ. 2013;5(1):157-8.

17. ten Cate O. AM last page: what entrustable professional activities add to a competency-based curriculum. Acad Med. 2014;89(4):691.

18. Ten Cate O, Scheele F. Competency-based postgraduate training: can we bridge the gap between theory and clinical practice? Acad Med. 2007;82(6):542-7.

19. Carraccio C, Englander R, Gilhooly J, Mink R, Hofkosh D, Barone MA, et al. Building a framework of entrustable professional activities, supported by competencies and milestones, to bridge the educational continuum. Acad Med. 2016; in press.

20. Ten Cate O, Chen HC, Hoff RG, Peters H, Bok H, van der Schaaf M. Curriculum development for the workplace using Entrustable
Professional Activities (EPAs): AMEE guide no. 99. Med Teach. 2015;37(11):983-1002.

21. Englander R, Flynn T, Call S, Carraccio C, Cleary L, Fulton T, et al. Core entrustable professional activities for entering residency - curriculum developers guide [Internet]. Washington DC; 2014. Available from www.aamc.org.

22. ten Cate O, Hart D, Ankel F, Busari J, Englander R, Glasgow N, et al. Entrustment decision making in clinical training. Acad Med. 2016;91(2):191-8.

23. ten Cate O. Entrustment as assessment: recognizing the ability, the right and the duty to act. J Grad Med Educ. 2016;8(2):263-4.

24. ten Cate O. Trust, competence, and the supervisor's role in postgraduate training. BMJ. 2006;333(7571):748-51. 